\section{Long-term visual prognosis of infantile-onset high myopia}

countries today, especially in Asia. ${ }^{1-3}$ Typically, juvenile-onset school myopia reveals myopic progression after the onset of the myopia. ${ }^{4-6}$ School children who appeared to be more myopic at the beginning were found to exhibit a more-rapid myopia progression rate. ${ }^{7}$ However, the clinical course of infantile-onset myopia would appear to be somewhat more mysterious and less discussed in the literature.

Usually, congenital myopia has been suggested to be represented by a generally stable refraction status. ${ }^{8-10}$ In addition, infantileonset high myopia may be one factor related to the development of ambyopia; thus, it is interesting and appears very important to investigate the visual prognosis of infantileonset myopia and to find the associated timerelated refractive changes. The generally used criterion for the diagnosis of congenital myopia is myopia of a high degree, greater than or equal to $-5.0 \mathrm{D}$, in a child of six years of age or less. ${ }^{11}$ Owing to the relative severity and prevalence of myopia in Taiwan being more substantial than most other countries, we decided to collect data pertaining to infantileonset myopic children based on the criterion of a spherical equivalence of greater than $-5.0 \mathrm{D}$ for a child prior to the age of five years. The principal goal of this study is, using a longitudinal study, to determine the clinical course of infantile-onset myopia.

\section{Materials and methods}

We used clinical records deriving between 1989 and 2002 inclusively as generated at the high myopia clinic of the National Taiwan University Hospital. Only those without any ocular or systemic disease associated with high myopia, ${ }^{12,13}$ such as Stickler or Marfan syndrome or history of prematurity, ${ }^{14}$ were eligible. A total of 57 myopic children featuring a spherical equivalent of over $-5.0 \mathrm{D}$ prior to the age of 5 years were recruited for this study.
Received: 13 April 2005 Accepted in revised form: 30 June 2005 Published online: 12 August 2005

\section{Introduction}

A rather high prevalence of school myopia is a significant public-health problem in many 
Table 1 reveals the baseline data. From the time of investigation, all children were followed up at the clinic every six months until they were more than 12 years old. The mean initial refractive error was $-10.55 \mathrm{D}(-5.25$ to $-13.63 \mathrm{D})$. All patients received their first pair of fully corrected glasses at the mean age of 3.66 years (1.8-5.5 years). The mean follow-up time was 9.36 years (8.2-11.9 years).

All children underwent a complete ophthalmological examination at their initial visit and semiannual visit, including a slit-lamp exam, best-corrected visual acuity testing, cycloplegic refraction assessment, fundoscopy, intraocular pressure examination, and biometric axial length determination. The cycloplegic refractive status was measured using an autorefractometer (Topcon RM-3000, Tokyo, Japan). The cycloplegic refraction was measured $30 \mathrm{~min}$ after the final of three successive drops of $1 \%$ tropicamide was instilled into the eyes at 5-min intervals. All values of the refractive status were rechecked by senior ophthalmologists using a retinoscope. Biometric axial length (including anteriorchamber depth, lens thickness, and total axial length) was measured using A-scan ultrasonography (Sonomed Ultrasound A-1500).

The difference between each group was checked by means of one-way analysis of variance (ANOVA) and the difference between two groups was tested using multiple-range tests, and the Turkey B-test. An independent Student's $t$-test was used to compare the difference between baseline data between girls and boys. A $P$-value less than 0.05 was considered to represent statistically significant difference. All data presented in tables are presented as group means \pm SD.

\section{Results}

Since we found no significant difference in baseline data between girls and boys, we therefore divided all myopic children into one of three groups according to the severity of the initial myopic refraction: Group A $(-5.0$ to $-7.75 \mathrm{D} ; n=15)$, Group B $(-8.0$ to $-10.75 \mathrm{D}$; $n=20)$, and Group C $(\leq-11.0 \mathrm{D} ; n=22)$. We also noted that there was no significant difference in the age at which glasses were initially fitted and no difference in the age of child at final follow-up between three groups $(P>0.1$; Table 2).

We found that the mean myopic progression rate for the children of Group C $(-0.07 \pm 1.38 \mathrm{D} /$ year $)$ was significantly slower than those values of Group B $(-0.21 \pm 1.56 \mathrm{D} /$ year $)$ and Group A $(-0.47 \pm 1.33 \mathrm{D} /$ year $)$ using ANOVA $(P<0.05)$. Further, the mean axial length elongation for the children of Group C $(0.09 \pm 0.39 \mathrm{~mm} /$ year) was also significantly less than those values for Group B $(0.22 \pm 0.38 \mathrm{~mm} /$ year $)$ and Group A $(0.31 \pm 0.27 \mathrm{~mm} /$ year $)(P<0.05)$.

If we considered the entire study suite of infantileonset myopia individuals, we found that $45 \%$ of these children showed either binocular progression or monocular progression, around $23 \%$ of children showed binocular stability, and $32 \%$ of children showed either binocular or monocular regression (Table 3). We found that children with a lower initial refractive level (Group A) reveal a greater proportion with myopic progression, either binocular or monocular, than did the children with higher level of myopic refraction initially (Groups B and C; $P<0.05)$. By contrast, children who featured a greater initial myopic refraction level (Groups B and C) did also exhibit a greater stability rate and even regression than

Table 1 Baseline data of children with infantile-onset high myopia

\begin{tabular}{lcc}
\hline Gender & Boys $(\mathrm{N}=26)$ & Girls $(\mathrm{N}=31)$ \\
\hline Age when first started wearing glasses (years) & $3.46 \pm 0.86(2-4.8)$ & $3.58 \pm 1.09(1.8-5.1)$ \\
Age of child at final follow-up visit (years) & $12.27 \pm 1.52(12.2-16.3)$ & $12.33 \pm 1.41(12.5-15.4)$ \\
Initial refraction (D) & $-9.43 \pm 3.84(-5.75$ to -13.12$)$ & $-9.67 \pm 3.38(-5.25$ to -13.63$)$ \\
Years of follow-up (years) & $9.20 \pm 1.56(8.2-11.8)$ & $9.42 \pm 1.74(8.4-11.9)$ \\
\hline
\end{tabular}

Table 2 The mean myopic progression and axial elongation among each myopic groups

\begin{tabular}{lcrc}
\hline & -5.0 to $-7.75 D$, & -8.0 to $-10.75 D$, & $\leq-11.0 D$, \\
Group A $(\mathrm{N}=15)$ & Group B $(\mathrm{N}=20)$ & $3.43 \pm 1.14$ & $3.42 \pm 0.84$ \\
Group C (N=22) & $12.31 \pm 1.34$ \\
Age when first started wearing glasses (years) & $3.56 \pm 0.98$ & $12.28 \pm 1.62$ & $12.31 \pm 1.42$ \\
Age of child at final follow-up visit (years) & $12.32 \pm 1.42$ & $-0.21 \pm 1.56$ & $-0.07 \pm 1.38^{*}$ \\
Myopia progression (D/year) & $-0.47 \pm 1.33$ & $0.22 \pm 0.38$ & $0.09 \pm 0.39^{*}$ \\
Axial length elongation (mm/year) & $0.31 \pm 0.27$ & \\
\hline
\end{tabular}

${ }^{*} P<0.05$. 
those of the children with a lower myopic refraction level initially $(P<0.05)$.

Further, we also found that eyes with myopic progression did reveal a lower level of myopic refraction initially $(-7.43 \pm 2.23 \mathrm{D})$ than those eyes with myopic regression $(-10.23 \pm 3.84 \mathrm{D})$ or myopic stability $(-9.13 \pm 3.46 \mathrm{D})(P<0.05)$. The increase of axial length in the eyes with myopic progression $(0.39 \pm 0.12 \mathrm{~mm} /$ year $)$ was greater than those eyes with myopic regression $(0.05 \pm 0.04 \mathrm{~mm} /$ year $)$ or myopic stability

$(0.14 \pm 0.09 \mathrm{~mm} /$ year $)(P<0.05)$. We also noted that those eyes featured a relatively stable level of myopic refraction and even regression of the myopia still did show some increase of axial length.

As Taiwanese people reveal a greater prevalence of myopia than most other countries, we were not surprised to find that most of the parents were myopes, although we did note that the proportion of children featuring binocular regression and whose parents both exhibited myopia (27.3\%) was substantially lower than those of the children exhibiting binocular myopic stability (53.8\%) or progression $(60 \%)$. In addition, children featuring binocular regression with either parent revealing high myopia did constitute a lower proportion of the test population $(18.2 \%)$ than those of the children revealing binocular myopic stability $(30.8 \%)$ or progression $(40 \%)$ (Table 4).

For the final best-corrected visual acuity, most of the children $(82.4 \%)$ revealed a visual acuity better than $20 / 40$, while $36.8 \%$ of children demonstrated vision was even better than 20/25 (Table 5). Further, the proportion of children from Groups B and C revealing a final visual acuity of less than $20 / 40$ was significantly greater than was the case for Group A $(P<0.05)$. We also observed that the proportion of children featuring one high myopic parent was similar among the three groups $(P>0.1)$.

\section{Discussion}

In this study, we found that the mean myopic progression rate for lower grades of high myopia ( -5.0 to $-7.75 \mathrm{D})$ was more rapid than those of the higher grades of high myopia ( -8.0 to -10.75 and $\leq-11.0 \mathrm{D}$ ). The ocular axial length elongation was also compatible with the myopic progression rate, higher levels of high

Table 3 Changes of myopic refraction of children with infantile-onset high myopia

\begin{tabular}{lcccc}
\hline & $\begin{array}{c}-5.0 \text { to }-7.75 \mathrm{D}, \\
\text { Group } A(\mathrm{~N}=15)(\%)\end{array}$ & $\begin{array}{c}-8.0 \text { to }-10.75 \mathrm{D}, \\
\text { Group B }(\mathrm{N}=20)(\%)\end{array}$ & $\begin{array}{c}\leq-11.0 \mathrm{D}, \\
\text { Group C }(\mathrm{N}=22)(\%)\end{array}$ & $\begin{array}{c}\text { Total } \\
(\mathrm{N}=57)(\%)\end{array}$ \\
\hline Binocular progression ( $\leq-0.75 \mathrm{D})$ & $6(40)$ & $5(25)$ & $4(18)$ & $15(26.3)$ \\
Binocular stability (between $-0.5 \mathrm{D}$ and $+0.5 \mathrm{D})$ & $2(13.3)$ & $5(25)$ & $6(27.2)$ & $13(22.8)$ \\
Binocular regression $(\geq+0.75 \mathrm{D})$ & $1(6.7)$ & $4(20)$ & $6(27.2)$ & $11(19.3)$ \\
Monocular progression and fellow eye stability & $4(26.7)$ & $3(15)$ & $4(18)$ & $11(19.3)$ \\
Monocular regression and fellow eye stability & $2(13.3)$ & $3(15)$ & $2(9.1)$ & $7(12.3)$ \\
Monocular regression and fellow eye progression & $0(0)$ & $0(0)$ & $0(0)$ & $0(0)$ \\
\hline
\end{tabular}

Table 4 Proportion of children with myopic progression, stability, and regression and number of parents with myopia

\begin{tabular}{|c|c|c|c|}
\hline & $\begin{array}{c}\text { Binocular myopic } \\
\text { progression }(\mathrm{N}=15)(\%)\end{array}$ & $\begin{array}{c}\text { Binocular myopic } \\
\text { stability }(\mathrm{N}=13)(\%)\end{array}$ & $\begin{array}{c}\text { Binocular myopic } \\
\text { regression }(\mathrm{N}=11)(\%)\end{array}$ \\
\hline None & $1(6.7)$ & $1(7.7)$ & $2(18.2)$ \\
\hline Either parent with myopia $(\leq-0.5 \mathrm{D})$ & $5(33.3)$ & $5(38.4)$ & $6(54.5)$ \\
\hline Both parents with myopia ( $\leq-0.5 \mathrm{D})$ & $9(60)$ & $7(53.8)$ & $3(27.3)$ \\
\hline Either parent with high myopia $(\leq-6 \mathrm{D})$ & $4(26.7)$ & $4(30.8)$ & $2(18.2)$ \\
\hline Both parents with high myopia ( $\leq-6 \mathrm{D})$ & $2(13.3)$ & $0(0)$ & $0(0)$ \\
\hline
\end{tabular}

Table 5 Visual outcome of infantile-onset high myopia

\begin{tabular}{lcccc}
\hline & $\begin{array}{c}-5.0 \text { to }-7.75 \mathrm{D}, \\
\text { Group } A(\mathrm{~N}=15)(\%)\end{array}$ & $\begin{array}{c}-8.0 \text { to }-10.75 \mathrm{D}, \\
\text { Group B }(\mathrm{N}=20)(\%)\end{array}$ & $\begin{array}{c}\leq-11.0 \mathrm{D}, \\
\text { Group C (N=22) (\%) }\end{array}$ & Total (N=57) (\%) \\
\hline Final visual acuity $>20 / 40$ & $15(100)$ & $17(85)$ & $15(68)$ & $47(82.4)$ \\
Final visual acuity $>20 / 25$ & $11(73.3)$ & $8(40)$ & $2(9.1)$ & $21(36.8)$ \\
\hline
\end{tabular}


myopia revealed a lower level of axial elongation than those of the lower grade of high myopia. These results were different to the course of school myopia. School myopia usually shows myopic progression after onset, the average rate of progression of myopia for a Singaporean study was $-0.60 \mathrm{D} /$ year. $^{5}$ These rates appear to be slightly greater than the average rate of progression of myopia of $-0.46 \mathrm{D} /$ year as reported for Hong Kong children aged between six and 17 years. ${ }^{6}$

In our study, we also found that $45 \%$ of studyparticipating children revealed either binocular or monocular progression, around $21 \%$ of children demonstrated binocular stability, and $32 \%$ of children exhibited either binocular or monocular regression. Infantile-onset myopia has frequently been suggested to represent a generally stable refraction status. ${ }^{8-10}$ We did note that the tendency toward myopic progression or regression appeared to be related to the degree of refractive error present. Myopic regression appeared to be most evident at the highest refraction levels. From such observations, we suspect that infantile-onset myopia is likely to demonstrate its own course.

In contrast, Blach ${ }^{10}$ reported that neonatal-onset myopia was much more likely to progress than it was likely to remain stable $(4.7: 1)$. Gambel ${ }^{15}$ reported myopic regression for $38 \%$ of studied eyes, although myopic progression was seen more frequently in this study (48\%). Further, from a study ${ }^{16}$ of 150 Russian children suffering from infantile-onset myopia, $57 \%$ of study-participating children revealed myopic progression while the remainder exhibited stable refraction. Therefore, we thought that although ocular stability may be relatively common in the early years of life for infantile-onset myopic children, but a number of the eyes studied herein demonstrated increases in myopia that appear to be similar to the changes noted in the longitudinal refraction follow-up studies of Hiatt et $a l^{9}$ and Blach. ${ }^{10}$ In a similar study $^{11}$ at the myopic clinic of the Manhattan Eye, Ear, and Throat Hospital, a group of 67 patients suffering from infantile myopia established by the criteria of earlyhistory myopia of 5D or more were followed-up for 4 years, approximately half of patient revealed binocular progression of their myopic status.

Clearly, we are left with the question of why higher level of infantile-onset myopia patients tend to exhibit a slower rate of myopic progression and why infantileonset myopia may, for some individuals, show myopic regression? Hereditary ${ }^{17-22}$ and environmental ${ }^{23-25}$ factors have been postulated to be responsible for myopia and myopic progression. Our study found that the incidence of children who revealed myopic progression or stability, or even regression may be related to whether or not their parent(s) suffered from myopia. The incidence of children featuring binocular regression and who had both parents suffering from myopia was lower than was the case for children who revealed binocular myopic stability or progression. Further, we did observe a smaller proportion of children exhibit binocular progression with their parents having a history of high myopia than those cases of children who featured binocular myopic stability or regression. Hiatt et $a l^{9}$ also noted that patients who featured a family history of myopia were more inclined to show myopic progression $(66 \%)$ than those who were without (54\%).

We also confirmed that increase in axial length of eyes undergoing myopic progression in this study.

Surprisingly, those eyes revealing stable refraction levels and even some featuring regression of the myopia still showed some increase in axial length in our study. We thought that this slight increase in axial length would likely be the normal growth rate of an eyeball during an individual's development. Therefore, we suspected that full correction of refractive errors at early life may elicit a clear image for the individual, and that this might halt the progression of myopia due to the inhibition of the normal growth of the eyeball, ${ }^{26}$ as well, the results of several animal studies using species such as chicks, ${ }^{27-29}$ tree shrews, ${ }^{30,31}$ and monkeys ${ }^{32}$ also indicated that form-deprivation myopia may be counterbalanced by the application of relatively short daily periods of unrestricted vision. However, the comprehension of the mechanism of myopic regression clearly needs to be explored by further study.

From the results of our study, it was apparent that more than $80 \%$ of infantile-onset high myopic children revealed a best-corrected visual acuity of greater than $20 / 40$. Around $37 \%$ of study-participating children revealed their best-corrected visual acuity achieved a level of 20/25. It would thus appear that the lower grades of high myopia would be associated with a better visual prognosis than those cases for a higher grade of high myopia. In summary, clinical course of the infantile high myopia is different to the school myopia. Usually, higher degree of high myopia showed a stable state of myopia, or even possible regression, whereas the lower grades of high myopia revealed a strong tendency to progress.

\section{Acknowledgements}

We gratefully thank Ting-Hsuan Chiang and Ho-Min Chen for their technical assistance.

\section{References}

1 Lin LLK, Shih YF, Hsiao CK, Chen CJ. Prevalence of myopia in Taiwanese schoolchildren, 1983 to 2000. Ann Acad Med Singapore 2004; 33: 27-33. 
2 Saw SM, Katz J, Schein OD, Chew SJ, Chan TK. Epidemiology of myopia. Epidemiol Rev 1996; 18: 175-187.

3 Zhao J, Pan X, Sui R, Munoz SR, Sperduto RD, Ellwein LB. Refractive error study in children: results from Shunyi District, China. Am J Ophthalmol 2000; 129: 427-435.

4 Jensen H. Myopia progression in young school children. Acta Ophthalmologica 1991; (Suppl 200): 24-29.

5 Tan N, Saw SM, Chee D, Lam DS, Cheng HM, Rajan U et al. Non-linear progression of myopia during school year. Invest Ophthalmol Vis Sci 1998; 39: S280.

6 Lam CS, Edwards M, Millodot M, Goh WS. A 2-year longitudinal study of myopia progression and optical component changes among Hong Kong schoolchildren. Optom Vis Sci 1999; 76: 370-380.

7 Braun CI, Freidlin V, Sperduto RD, Milton RC, Strahlman ER. The progression of myopia in school age children: data from the Columbia Medical Plan. Ophthalmol Epidemiol 1996; 3: 13-21.

8 Lecaillon-Thibon B. Long-term follow-up studies of myopia. Doc Ophthalmol 1981; 28: 29-32.

9 Hiatt RL, Costenbader FD, Albert DG. Clinical evaluation of congenital myopia. In: Curtin BJ (eds). The Myopias: Basic Science and Clinical Management, 1st ed. Harper and Row: New York, 1985, pp 390.

10 Blach RK. The nature of degenerative myopia. In: Curtin BJ (ed). The Myopias: Basic Science and Clinical Management, 1st ed. Harper and Row: New York, 1985, pp 390.

11 Curtin BJ. The Myopias: Basic Science and Clinical Management, 1st ed. Harper and Row: New York, 1985, pp 177.

12 Marr JE, Halliwell-Ewen J, Fisher B, Soler L, Ainsworth JR. Association of high myopia in childhood. Eye 2001; 15: 70-74.

13 Logan NS, Gilmartin B, Marr JE, Stevenson MR, Anisworth JR. Community-based study of the association of high myopia in children with ocular and systemic disease. Optom Vis Sci 2004; 81: 11-13.

14 Saw SM, Chew SJ. Myopia in children born premature or with low birth weight. Acta Ophthalmol Scand 1997; 75: 548-550.

15 Gambel RC. High congenital myopia with convergent strabismus. In: Curtin BJ (ed). The Myopias: Basic Science and Clinical Management, 1st ed. Harper and Row: New York, 1985, pp 390.

16 Trinchuck VV, Ermolaeva LT. Long term development of congenital myopia. In: Curtin BJ (ed). The Myopias: Basic Science and Clinical Management, 1st ed. Harper and Row: New York, 1985, pp 391.

17 Mutti DO, Mitchell GL, Moeschberger ML, Jones LA, Zadnik K. Parental myopia, near work, school achievement, and children's refractive error. Invest Ophthalmol Vis Sci 2002; 43: 3633-3640.
18 Goss DA. Nearwork and myopia. Lancet 2000; 356: 1456-1457.

19 Saw SM, Nieto FJ, Katz J, Schein OD, Levy B, Chew SJ. Factors related to the progression of myopia in Singaporean children. Optom Vis Sci 2000; 77: 549-554.

20 Saw SM, Nieto FJ, Katz J, Chew SJ. Estimating the magnitude of close-up work in school-age children: a comparison of questionnaire and daily instruments. Ophthalmic Epidemiol 1999; 6: 291-301.

21 Saw SM, Hong CY, Chia KS, Stone RA, Tan D. Near work and myopia in young children. Lancet 2001; 357: 390

22 Saw SM, Chua WH, Hong CY, Wu HM, Chan WY, Chia KS et al. Near work in early-onset myopia. Invest Ophthalmol Vis Sci 2002; 43: 332-339.

23 Pacella R, McLellan J, Grice K, Del Bono EA, Wiggs JL, Gwiazda JE. Role of genetic factors in the etiology of juvenile-onset myopia based on a longitudinal study of refractive error. Optom Vis Sci 1999; 76: 381-386.

24 Young TL, Ronan SM, Drahozal LA, Wildenberg SC, Alvear $\mathrm{AB}$, Oetting WS et al. Evidence that a locus for familial high myopia maps to chromosome 18p. Am J Hum Genet 1998; 63: 109-119.

25 Young TL, Ronan SM, Alvear AB, Wildenberg SC, Oetting WS, Atwood LD et al. A second locus for familial high myopia maps to chromosome 12q. Am J Hum Genet 1998; 63: 1419-1424.

26 Gwiazda J, Thorn F, Bauer J, Held R. Emmetropization and the progression of manifest refraction in children followed from infancy to puberty. Clin Vis Sci 1993; 8: 337-344.

27 Wildsoet C, Wallman J. Choroidal and scleral mechanism of compensation for spectacle lenses in chicks. Vis Res 1995; 35: 1175-1194.

28 Napper GA, Brennan NA, Barrington M, Squires M, Vessey GA, Vingrys AJ. The duration of normal visual exposure necessary to prevent form deprivation myopia in chicks. Vis Res 1995; 35: 1337-1344.

29 Napper GA, Brennan NA, Barrington M, Squires M, Vessey GA, Vingrys AJ. The effect of an interrupted daily period of normal visual stimulation on form deprivation myopia in chicks. Vis Res 1997; 37: 1557-1564.

30 Norton TT, McBrien NA. Normal development of refractive state and ocular component dimensions in the tree shrew. Vis Res 1992; 32: 833-842.

31 Shaikh AW, Siegwart JT, Norton TT. Effect of interrupted lens wear on compensation for a minus lens in tree shrews. Optom Vis Sci 1999; 76: 308-315.

32 Smith EL, Hung LF, Kee Cs, Qiao Y. Effects of brief periods of unrestricted vision on the development of formdeprivation myopia in monkeys. Invest Ophthalmol Vis Sci 2002; 43: 291-299. 